\title{
Free Radicals Scavenging Activities of Low Molecular Weight Sodium Alginate (LMWSA) from Sargassum polycystum, Produced by Thermal Treatment
}

\author{
Ervia Yudiati $^{1}$, Delianis Pringgenies ${ }^{1}$, Ali Djunaedi ${ }^{1}$, Zaenal Arifin ${ }^{2}$, and Agung Sudaryono ${ }^{3}$ \\ ${ }^{1}$ Department of Marine Science, Diponegoro University, Semarang, Indonesia \\ ${ }^{2}$ Brackishwater Aquaculture Development Centre, Jepara, Central Java, Indonesia \\ ${ }^{3}$ Department of Fisheries, Diponegoro University, Semarang, Indonesia, Indonesia \\ ${ }^{*}$ Corresponding author: eyudiati@gmail.com
}

Received: 25 April 2018; Accepted: 24 Mei 2018

\begin{abstract}
Ervia Yudiati, Delianis Pringgenies, Ali Djunaedi, Zaenal Arifin, and Agung Sudaryono. 2018. Free Radicals Scavenging Activities of Low Molecular Weight Sodium Alginate (LMWSA) from Sargassum polycystum, Produced by Thermal Treatment. Aquacultura Indonesiana, 19 (1): 21-27. In this study, the effects of alginate from Sargassum polycystum molecular reduction by thermal heating on DPPH anti radical scavenging activity were investigated. Raw alginate as the control treatment was heated at $140^{\circ} \mathrm{C}$ in a laboratory oven for different time courses 1.5, 4.5, and 7.5 hours. The assessment of molecular weight, UV-visible and FTIR spectroscopic studies were applied. By heat treatment, molecular weight of polymer was decreased in a timedependent manner, though there is no significant difference between $4.5 \mathrm{~h}$ and $7.5 \mathrm{~h}$ samples. The UV-visible spectroscopic studies pointed that there was a new absorption band between 250 and $290 \mathrm{~nm}$ in alginate heated treatments. The higher antiradical scavenging activity were reached from $1.5 \mathrm{~h}$ and $4.5 \mathrm{~h}$ treatments $(19.83 \%$ and $20.07 \%)$. Interestingly, the antiradical scavenging activity of the longest heating treatment $(7.5 \mathrm{~h})$ was reduced (16.85\%), similar to the raw alginate (17.89\%). Prolonged heat treatments influenced the antioxidant activity and reduced the ability of donate electrons or hydrogen atoms to inactivate this radical action.
\end{abstract}

Keywords: Alginate; Antioxidant; LMWSA; Sargassum

\section{Introduction}

Alginate is a linear polysaccharide which constructed as $\alpha$-L-guluronate $(\mathrm{G})$ and $\mathrm{C} 5$ epimer $\beta$-D-mannuronate $(\mathrm{M})$, homopolymeric blocks (polymannuronate and polyguluronate). Guluronate and mannuronate are uronate with carboxyl groups at $\mathrm{C} 5$, every configuration shows the difference between two pyranose (Pawar and Edgar, 2011). These biopolymers and polyelectrolyte (Donati and Paoletti, 2009) was kept in the brown seaweed cell wall including Sargassum polycystum (Draget and Taylor, 2011; Isnansetyo et al., 2014). Sargassum siliquosum, originally from Indonesia resulted the best yield $(40.34 \%)$ compare to others (Yudiati and Isnansetyo, 2017).

Antioxidants inhibit or prevent oxidation of a substrate, and evolve to protect biological systems against damage induced by ROS (reactive oxygen species) (Hwang et al., 2010). Modern people aware that there are severe side effects of many synthesized chemicals which act as a free radical scavenger (Melo-Silveira et al., 2014). Nowadays, researchers are trying to use alginates as a natural product. Several efforts have been done to increase the antioxidant activity by breaking the polymer chain into oligosaccharide. Antioxidants have widespread applications in medical and food industry (Sindhi et al., 2013; Fawzy et al., 2017).

Polysaccharides are depolymerized by cleavage of the glycosidic bonds (Kelishomi et al., 2016). In alginate, glycosidic bonds are susceptible to various degradation mechanisms (Holme et al., 2003). Some researchers had depolymerized alginate by reducing (Smidsrod et al., 1963) and oxidizing (Li et al., 2010). Another experiments have done by application with some agents such as acidic (Haug et al.,1963), enzymatic (Falkeborg et al., 2014) as well as alkaline (Haug et al., 1967). Several methods have also done by gamma (Choi et al., 2010) x-ray (Daar et al., 2010), and UV irradiation (Burana-osot et al., 2009) as well as thermal heating (Holme et al., 2001; Holme et al., 2003; Choi et al., 2010; Li et al., 2010; Nam et al., 2010; Moussout et al., 2016). The thermal methods to alginate depolimerasation is more preferable. This due to the fact that the enzymatic method requires longer time (Aida et al., 2010; Zhao et al., 2012). Moreover, the weakness of other methods is using harsh chemicals (Aida $e t$ al., 2010). Other advantages of thermal treatment method are simpler, more cost-effective and 
accessible compared with enzymatic and radiation treatments (Kelishomi et al., 2016). The objetive of our study, was depolymerized the alginate from local seaweed by heat in laboratory oven at $140^{\circ} \mathrm{C}$. The determination of molecular weight and size the heat-treated alginate was done by viscometry. The confirmation of new functional groups were determined by UV-visible and FTIR spectroscopies. The determination of antioxidant activity of heat alginate products was studied by DPPH superoxide-radical scavenging assay.

\section{Materials and Methods}

\section{Sodium Alginate Extraction of Sargassum polycystum}

S. polycystum was collected from Teluk Awur Bay, Jepara, Central Java, Indonesia (Figure 1). The collection were then cleaned, rinsed with fresh water and then dried up in room temperature to avoid direct exposure from sunlight.

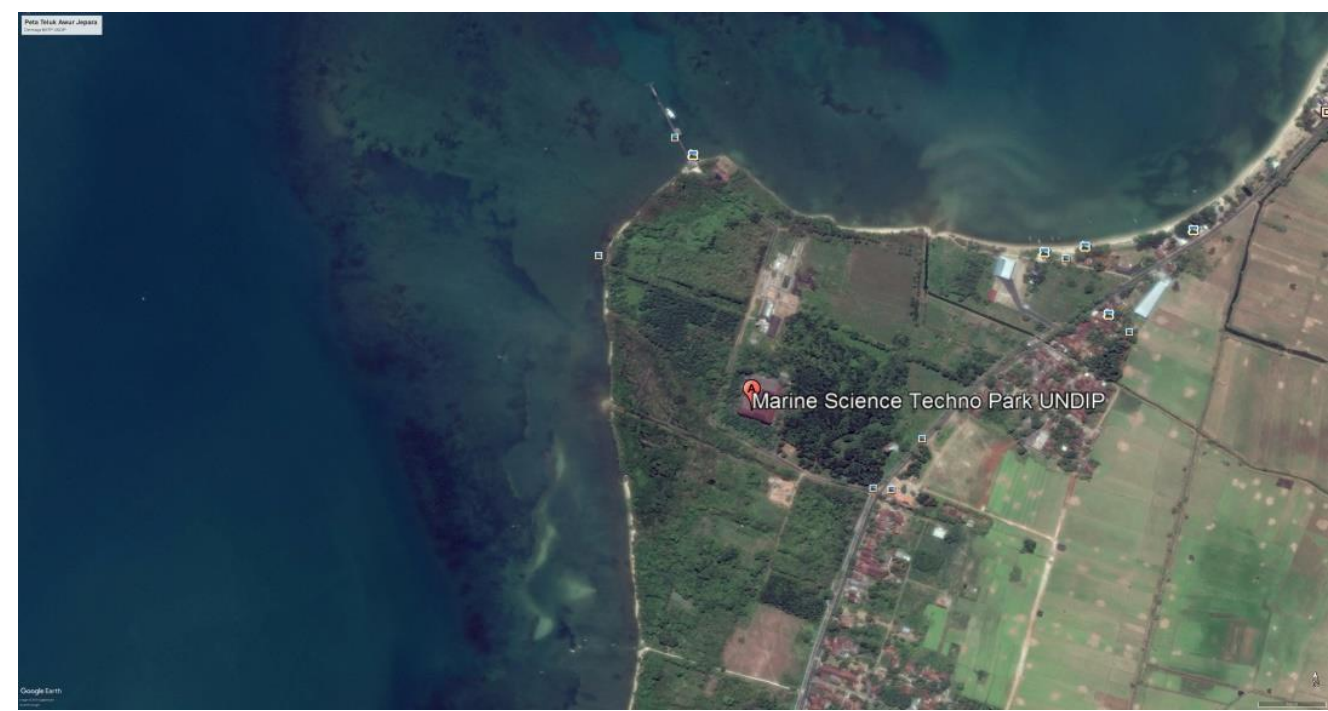

Figure 1. Map of Teluk Awur Bay, Jepara, Central Java. The map of imagery satellite was downloaded from Googlemaps ${ }^{\circledR}$.

The alginate extract was prepared based on the methods of Jork et al. (2000). The alginate was prepared by $24 \mathrm{~h}$ extraction with $5 \% \mathrm{Na}_{2} \mathrm{CO}_{3}$. The extract was then filtered. The supernatant was added with $0.13 \mathrm{M} \mathrm{KCl}$ and precipitated with $96 \%$ ethanol and then stirred well. Centrifugation was then performed at 3,500 rpm for $5 \mathrm{~min}$. The alginate was collected and then dried overnight in the oven at $60^{\circ} \mathrm{C}$.

\section{Thermal treatment of sodium alginate}

Raw alginate as the control treatment from S. polycystum was heated at $140^{\circ} \mathrm{C}$ in a laboratory oven for different time courses: $1.5,4.5$, and $7.5 \mathrm{~h}$. Those three time courses were applied as treatments.

\section{Assessment of Molecular Weight}

Molecular weight of raw alginate $(\mathrm{C})$ and heat-treated alginates were calculated from the Mark-Houwink equation:

$$
[\eta]_{\text {int }}=k M_{v}^{a}
$$

where $\mathrm{Mv}$ and $[\eta]$ int are the molecular weight of the polymer and the intrinsic viscosity, respectively.
Also, the constants " $\mathrm{k}$ " and " $\mathrm{a}$ " for alginate are $7.3 \times 10^{3}$ and 0.92 , respectively (Pamies et al., 2010).

Oswald Viscometer was used to determine specific viscosities $\left(\eta_{\mathrm{sp}}\right)$ of diluted control alginate and heat-treated alginate solutions (Celik et al., 2013). The intrinsic viscosity $\left([\eta]_{\text {int }}\right)$ was determined by extrapolating the $\left[\eta_{\mathrm{sp}}\right] / \mathrm{C}$ vs. C curve to zero.

\section{Spectroscopic studies}

UV-visible spectroscopy

Depolymerization process was examined by UV-visible spectroscopy. Aqueous solutions of alginate samples were prepared with distillation water. Concentration of the solution was 0.01 (w/v). UV-visible spectroscopy of raw alginate and heat-treated alginates were performed by Carry 100 Bio spectrophotometer in $200-400 \mathrm{~nm}$ range.

\section{Fourier-Transform IR (FT-IR) spectroscopy}

The characterizations of alginates were determined spectrophotometrically by signal vibration using Fourier Transformed-Infra Red. Sample of alginate was mixed with $\mathrm{KBr}(1: 20$ w/w) and was prepared in pellets form. It was 
then recorded at the wavelength region between $4000-500 / \mathrm{cm}$ using a Thermo Nicolet 380 FTIR (Germany).

\section{Antioxidant activity}

\section{$D P P H$ radical scavenging activity assay}

The assay was performed relied on a modified method described by Banerjee et al. (2005). The concentration of samples was $1 \mathrm{w} / \mathrm{v}$. An aliquot of each sample $(100 \mu \mathrm{L})$ was mixed with $100 \mu \mathrm{L}$ of $0.1 \mathrm{mM}$ DPPH (prepared with absolute ethanol) and then followed by incubation for $30 \mathrm{~min}$. The absorbance of each sample was read at $517 \mathrm{~nm}$ using a microplate reader $(R$ Biopharm Well Reader, Germany). The percentage of scavenged DPPH was calculated using the following equation:

DPPH scavenging activity $(\%)=[(\mathrm{Ac} / \mathrm{As}] / \mathrm{Ac} \times 100$

where $\mathrm{Ac}$ is the absorbance of the control (100 $\mu \mathrm{L}$ of ethanol with $100 \mu \mathrm{L}$ of the DPPH solution) and As is the absorbance of the sample.

\section{Statistical analysis}

All data were subjected to one-way analysis of variance (ANOVA) at the level of significance of 0.05. A multiple comparison (LSD) test was used to examine significant differences among treatments using IBM SPSS Statistics 20 computer software.

\section{Results and Discussion}

\section{Determination of molecular weight}

The molecular weight of raw (C) and heattreated alginates was shown in Figure 2. It is clearly shown by heat treatment, molecular weight of polymer was decreased in a time-dependent manner $(\mathrm{P}<0.05)$. But there was no significant difference between $4.5 \mathrm{~h}$ and $7.5 \mathrm{~h}$ samples by applying this technique. Reduction of molecular weight is probably caused by shortening the polymer chain due to the fact of glycosidic bond breakage. Some researchers reported low molecular alginate by heat treatments have been agreed with this result. The special glycosidic bond in the polysaccharide unit have shown, and the stretching of C-O-C was appeared in the glucose ring (Moussout et al., 2016). Li et al. (2010) found the cleavage of glycosidic linkages of chitosan and a thermal heating programmed dry oven for $52 \mathrm{~h}$ at $90^{\circ} \mathrm{C}$ dry oven performed similarly activities
(Choi et al., 2010). This included depolimerisation of other hydrocarbon alginates (Holme et al., 2003, Kelishomi et al, 2016) as well as chitosan (Holme, et al., 2001; Holme et al., 2008), and hyaluronic acid (Yue et al., 2012).

\section{Spectroscopic studies}

\section{FT-IR Spectroscopic Analysis}

The FT-IR spectra from raw (a) and heat treated (b, c, d) alginate compared to the standard alginate (Sigma, USA) can be seen on Figure 3. There is a wide band at $3400 / \mathrm{cm}$ shows the sign of O-H stretching vibration. The signal at 2900 and $1600 / \mathrm{cm}$ is related to $\mathrm{C}-\mathrm{H}$ stretching vibration and $\mathrm{O}-\mathrm{C}-\mathrm{O}$ carboxylate bound asymmetrically. The spectra around $1401 / \mathrm{cm}$ is signed of the deformation vibration of $\mathrm{C}-\mathrm{OH}$, which contributes of O-C-O symmetrically stretching vibration from carboxylate group (Mathlouti and Keoning 1987; Silverstein et al, 1991). The band observed about $1300 / \mathrm{cm}$ was predicted from deformation of C-C-H $(\mathrm{O}-\mathrm{C}-\mathrm{H})$ attributes, 1095 band was pointed the stretching from C-O vibration at pyranose ring. The stretching formation from $\mathrm{C}-\mathrm{C}$ vibration was measured at $1033 / \mathrm{cm}$. The indication of uronic acid which formatted by the $\mathrm{C}-\mathrm{O}$ group was observed at $946 / \mathrm{cm}$ wavelength number (Chandia et al, 2001, 2004). Furthermore, the recorded signal at around $900 / \mathrm{cm}$ showed the existence of asymmetric $\alpha$-L-gulopyranuronate vibration ring (Chandia et al, 2001; Mathlouthi and Koening, 1987).

Generally, the spectral pattern were not change by different alginate alkaline methods and there were no additional bands appeared. Eventhough, some differences can be observed in the height and shape of certain absorption bands. The peak and characteristic broad absorbance band at around $3400 / \mathrm{cm}$ wavenumber increased remarkably with the increase in treatment time, which is associated with the $-\mathrm{OH}$ functional group. At 3400/cm wavenumber, the transmittance of raw and heat treated $(1.5 ; 4.5 \mathrm{~h})$ were getting reduced $(40 ; 35$ and 20\%), respectively. At $7.5 \mathrm{~h}$ heat treated, the transmittance getting higher, and reached $27 \%$. This characteristics reveal the facts that antioxidant activity is highly donated from hidrogen kation which contribute the inhibition of free radicals. Furthermore, it is marked that there is some different absorbance intensity around $1600 / \mathrm{cm}$ and slighlty different characteristics at fingerprint area $(750-950 / \mathrm{cm})$. 


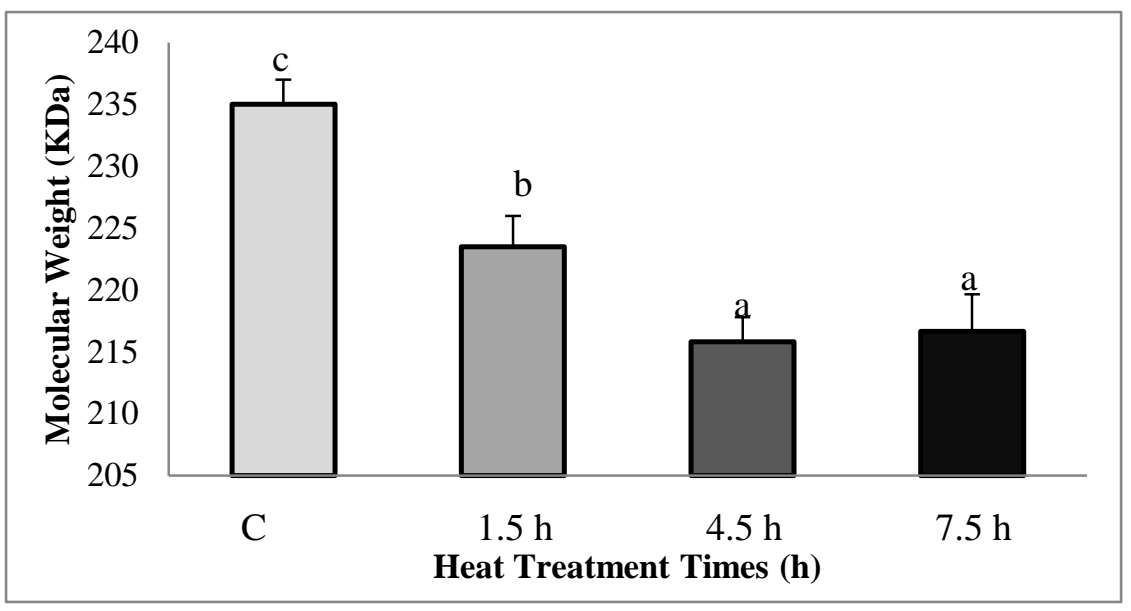

Figure 2. Molecular weight raw and heat-treated sodium alginates of $S$. polycystum at heat treatment time (hours). Data with different letters indicate the significant difference $(\mathrm{p}<0.05)$.

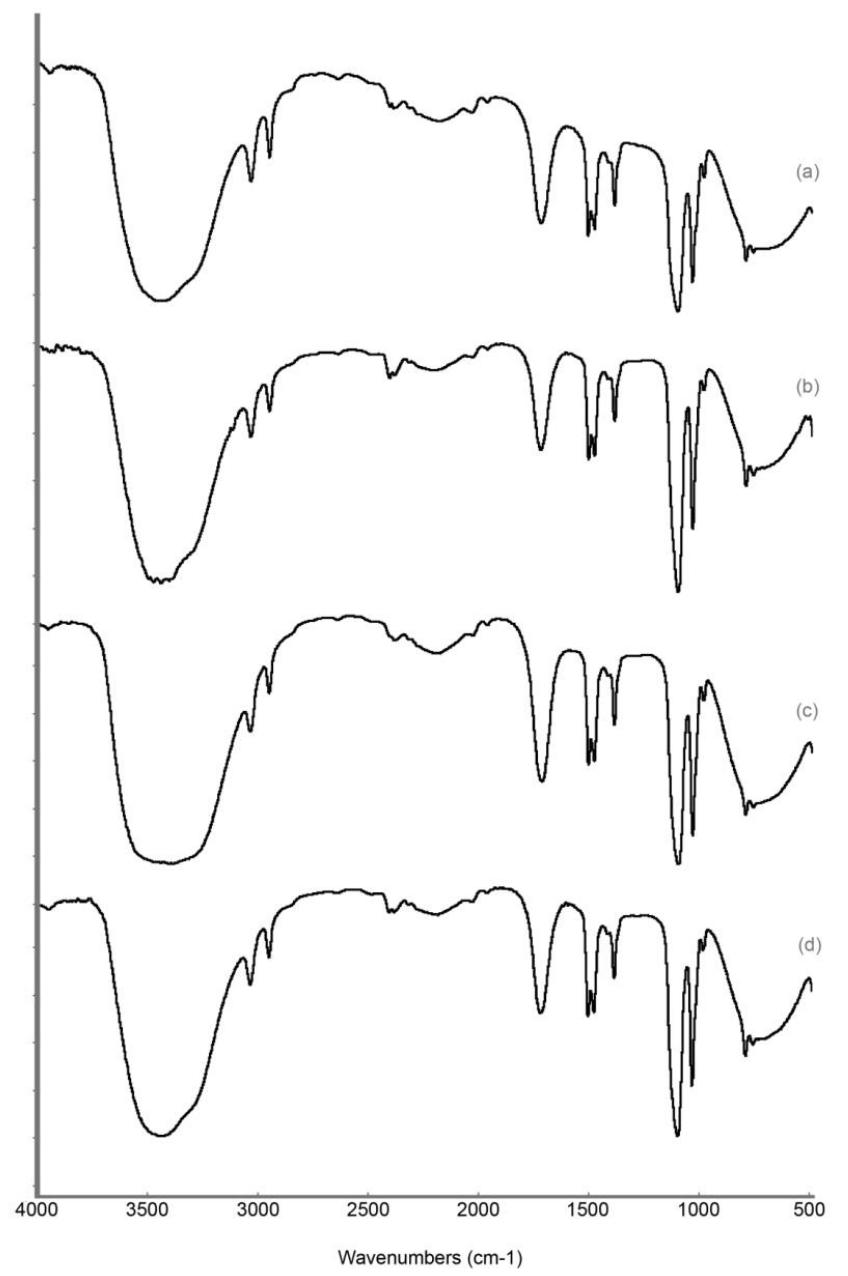

Figure 3. The FT-IR spectra of raw (A), $1.5 \mathrm{~h}(\mathrm{~B}) ; 4.5 \mathrm{~h}(\mathrm{C}) ; 7.5 \mathrm{~h}(\mathrm{D})$ of heat treated alginate from Sargassum polycystum

\section{UV-visible Spectroscopic Analysis}

Figure 4. is showing the UV spectra of raw alginate and heat-treated alginates treatments. The peak intensity increased according to the time of heat treatment. There was a new absorption band around $250 \mathrm{~nm}$. Formation of peaks around $240 \mathrm{~nm}$ spectral regions was attributed to the formation of carbonyl groups. Previous studies on depolymerizing of seaweed polysaccharide (Choi et al., 2009), chitosan (Ulan'ski and Rosiak, 1992) and alginate (El-Mohdy, 2017; Burana-osot 
et al., 2009), hyaluronic acid (Daar et al., 2010) by gamma and $\mathrm{x}$-ray irradiation, assigned these peaks to the same functional groups. Moreover, Choi et al. (2010) used thermal treatment to degrade hyaluronic acid, alginate (Kelishomi et al., 2016) and reported the presence of the similar band peaks. Li et al. (2010) reported the temperature and activation energy of the degradation are related to the weight fraction of the cupric ion of quaternized chitosan. The native hyaluronic acid treated with ozone can be converted into the low-molecular-weight hyaluronic acid (Yue, 2012). Therefore, it was indicated the final products of thermal treatment were similar to the products of the radiation treatment of alginate. In the heat treatments, producing the new carbonyl groups were positively occured. In their research previous research, absorbance at $234 \mathrm{~nm}$ indicates the formation and existence of double bonds between C-4 and C-5 in the pyranose rings (Kelishomi et al., 2016; Falkeborg et al.,2014; Thomas et al., 2013).

\section{DPPH radical scavenging activity assay}

DPPH has been extensively used as a free radical to evaluate antioxidant substances that reduce DPPH by donating hydrogen to form the non-radical DPPH-H. The DPPH radical scavenging activity of raw alginate and heattreated alginates treatments were shown in Figure 5. The employment of different heat treatment produced alginates with diverse DPPH scavenging activities. The results exhibited a concentration-dependent antiradical activity.

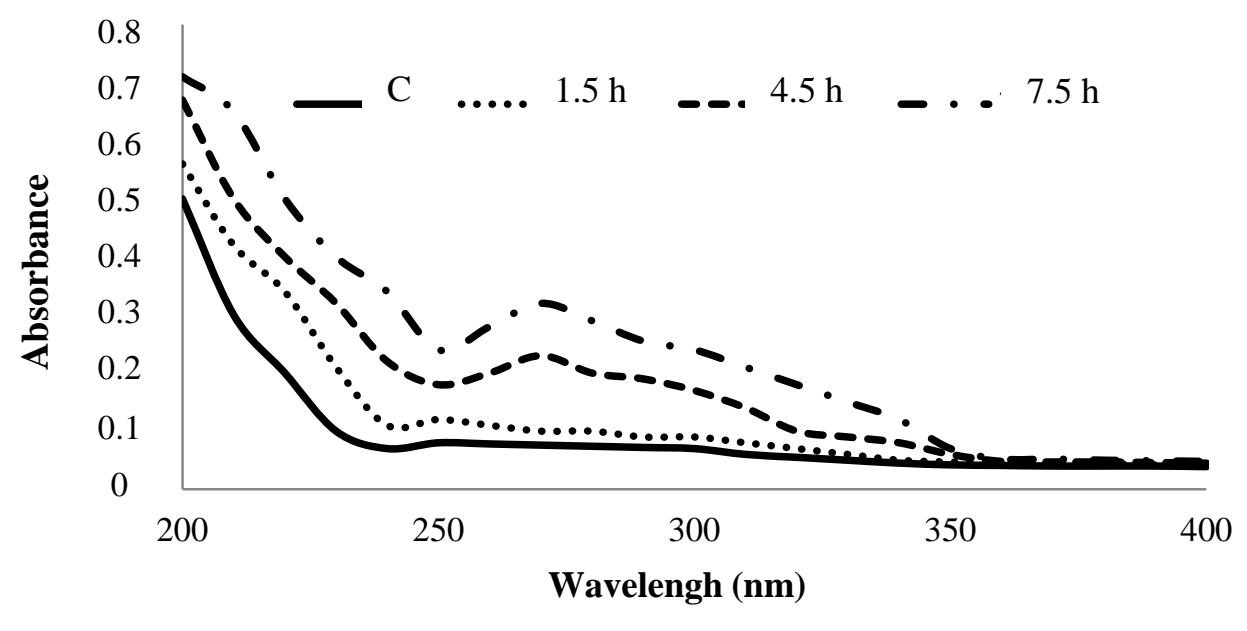

Figure 4. UV spectra of raw sodium alginate (C) and heat-treated alginates (hours) of S. polycystum.

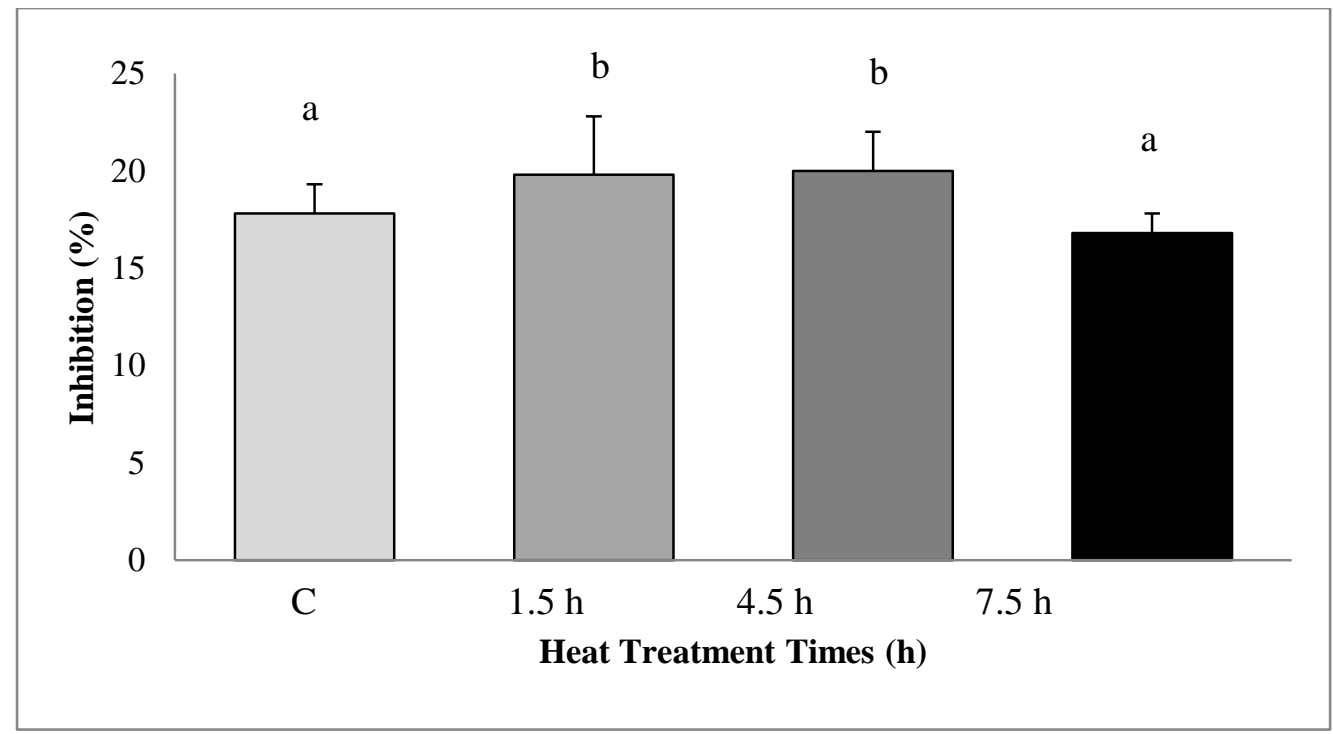

Figure 5. Percentage inhibition of sodium alginate at raw (C) and heat treated alginates $(1.5 \mathrm{~h} ; 4.5 \mathrm{~h}$ and $7.5 \mathrm{~h}$ ) of $S$. polycystum Data with different letters indicate the significant difference $(\mathrm{p}<0.05)$. 
The highest antiradical activity was reached unsignificantly different at $1.5 \mathrm{~h}(19.83 \%)$ and $4.5 \mathrm{~h}(20.07 \%)$ treatment. In contrast, the intensity of the longest heating treatment $(7.5 \mathrm{~h})$ was reduced to $16.85 \%$, similar to the raw alginate $(17.89 \%)$. The ability to scavenge free radical is presumably because the donate electrons or hydrogen atoms to inactivate this radical action (Falkeborg et al., 2014). In general, the antiradical activity of raw alginate and $7.5 \mathrm{~h}$ treatments was lower. Our results conforming the different data from Kelishomi et al., (2016) data. The researchers were applicated alginate from the commercial product. High and certain thermal heating technique allowed the degradation of the hydrochemical compound (Holme et al., 2003; Holme et al., 2008; Yudiati et al., 2018). This study pointed that this thermal heating technique is time dependent manner and supported by the molecular weight, transmittant intensity of spectroscopic as well as the DPPH radical scavenging activity data. Research from Aida et al (2010) supported similar phenomenon. The decomposition reaction of alginate is promoted by increasing temperature, however, the monosaccharide yields decrease with increasing temperature. Different from others, this finding become more interesting since we prepared the alginate extraction from local Sargassum polycystum in simple methods.

\section{Conclusion}

Producing the low molecular weight of sodium alginate by heated treatments was simple, safe and effective. Eventhough, this application is time dependent manner. The best antioxidant activity which contributes by hydrogen donor to inactivate the radical action were produced at 1.5 and $4.5 \mathrm{~h}$ at $140^{\circ} \mathrm{C}$.

\section{Acknowledgement}

Part of this study was financially supported by a grant from the Faculty of Fisheries and Marine Sciences, Diponegoro University, contract no. 36/UN7.5.10/HK/2017. The authors would like to express the appreciation to those who helped support this research at The Tropical Marine Biotechnology Laboratory, Diponegoro University and Brackishwater Aquaculture Development Center, Jepara.

\section{References}

Aida, T.M., T. Yamagata, M. Watanabe, and R.L. Smith Jr. 2010. Depolymerization of sodium alginate under hydrothermal conditions. Carbohydr. Polym., 80(1): 296-302.

Banerjee A., N. Dasgupta, and B. De. 2005. In vitro study of antioxidant activity of syzigium cumini fruit. Food Chem., 90(4): 727-733.

Burana-osot, J., S. Hosoyama, Y. Nagamoto, S. Suzuki, R.J. Linhardt, and T.Toida. 2009. Photolytic depolymerization of alginate. Carbohydrate Research, 344(15): 2023-2027.

Celik E., I. Keskin, I. Kayatekin, F. Ak Azem, and E. Özkan. 2013. $\mathrm{Al}_{2} \mathrm{O}_{3}-\mathrm{TiO}_{2}$ thin films on glass substrate by sol-gel technique. Mater. Charact., 58(4): 349-357.

Chandia, N.P., B. Matsuhiro, and A.E. Va'squez. 2001. Alginic acids in Lessonia trabeculata: characterization by formic acid hydrolysis and FT-IR spectroscopy. Carbohydr. Polym., 46(1): 81-87.

Chandia, N.P., B. Matsuhiro, E. Mejias, and A. Moenne. 2004. Alginic acids in Lessonia vadosa: Partial hydrolysis and elicitor properties of the polymannuronic acid fraction. J. Appl. Phycol., 16(2): 127-133.

Choi J.I., H.J. Kim, J.H. Kim, M.W. Byun, B.S. Chun, D.H. Ahn, Y.J. Hwang, D.J. Kim, G.H. Kim, and J.W. Lee. 2009. Application of gamma irradiation for the enhanced physiological properties of polysaccharides from seaweeds. Appl. Radiat. Isot., 67(7-8): 1277-1281.

Choi, J.I., J.K. Kim, J.H. Kim, D.K. Kweon, and J.W. Lee. 2010. Degradation of hyaluronic acid powder by electron beam irradiation, gamma ray irradiation, microwave irradiation and thermal treatment: A comparative study. Carbohydr. Polym., 79(4): 1080-1085.

Daar, E., L. King, A. Nisbet, R.B. Thorpe, and D.A. Bradley. 2010. Viscosity changes in hyaluronic acid: irradiation and rheological studies. Appl. Radiat. Isot., 68(4-5): 746-750.

Donati, I. and S. Paoletti. 2009. Material properties of alginates. In: B.H.A. Rehm (Ed.) Alginates: Biology and Applications. Springer, pp. 1-53.

Draget, K.I. and C. Taylor. 2011. Chemical, physical and biological properties of alginates and their biomedical implications. Food Hydrocoll., 25(2): 251-256.

El-Mohdy, A.H.L. 2017. Radiation-induced degradation of sodium alginate and its plant growth promotion effect. Arabian Journal of Chemistry, 10(1): 431-438.

Falkeborg, M., L-Z Cheong, C. Gianfico, K.M. Sztukiel, K. Kristensen, M. Glasius, X. Xu, and Z. Guo. 2014. Alginate oligosaccharides: enzymatic preparation and antioxidant property evaluation. Food Chem., 164(1): 185-194.

Fawzy, M.A., M. Gomaa, A.F. Hifney, and K. M. Abdel-Gawad. 2017. Optimization of alginate alkaline extraction technology from Sargassum latifolium and its potential 
antioxidant and emulsifying properties. Carbohydr. Polym., 157(10): 1903-1912.

Haug, A., B. Larsen, and O. Smitsrod. 1963. The degradation of alginates at different $\mathrm{pH}$ value. Acta Chem. Scand., 17: 1466-1468.

Haug, A., B. Larsen, and O. Smitsrod. 1967. Alkaline degradation of alginate. Acta Chem. Scand., 21: 2859-2870.

Holme, H.K., L. Davidsen, A. Kristiansen, and O, Smidsrød. 2008. Kinetics and mechanisms of depolymerization of alginate and chitosan in aqueous solution. Carbohydr. Polym., 73(4): 656-664.

Holme, H.K., H. Foros, H. Pettersen, M. Dornish, and O. Smidsrød. 2001. Thermal depolymerization of chitosan chloride. Carbohydr. Polym., 46(3): 287-294.

Holme, H.K., K. Lindmo, A. Kristiansen, and $O$. Smidsrød. 2003. Thermal depolymerization of alginate in the solid state. Carbohydr. Polym., 54(4): 431-438.

Hwang, P.A., C.H. Wu, S.Y. Gau, S.Y. Chien, and D.F. Hwang. 2010. Antioxidant and immunestimulating activities of hot-water extract from seaweed Sargassum hemiphyllum. Journal of Marine Sciene and Technology, 18(1): 41-46.

Isnansetyo, A., H.M. Irpani, T.A. Wulansari, and N. Kasanah. 2014. Oral administration of alginate from a tropical brown seaweed, Sargassum sp. to enhance non-spesific defense in walking catfish (Clarias sp.) Aquacultura Indonesiana, 15(1): 73-80.

Kelishomi, Z.H., B. Goliaei, H. Mahdavi, A. Nikoofar, M. Rahimi, A. A. Moosavi-Movahedi, F. Mamashli and B. Bigdeli. 2016. Antioxidant activity of low molecular weight alginate produced by thermal treatment. Food Chem., 196: 897-902.

Li, S-D., C-H. Zhang, J-J. Donga, C-Y. Oua, W-Y. Quana, L. Yanga and X-D. Shea. 2010. Effect of cupric ion on thermal degradation of quaternized chitosan. Carbohydr. Polym. 81(2): 182-187.

Mathlouthi, M. and J.L. Koenig. 1987. Vibrational spectra of carbohydrates. Adv. Carbohydr. Chem. Biochem., 44: 7-89.

Melo-Silveira R., G. Fidelis, R. Viana, V. Soeiro, R. Silva, D. Machado, and R.H. Oliveira. 2014. Antioxidant and antiproliferative activities of methanolic extract from a neglected agricultural product: Corn cobs. Molecules, 19(4): 5360-5378.

Moussout, H., H. Ahlafi, M. Aazza, and M. Bourakhouadar. 2016. Kinetics and mechanism of the thermal degradation of biopolymers chitin and chitosan using thermogravimetric analysis. Polymer Degradation and Stability, 130: 1-9.

Nam, Y.S.,W. H. Park, D. Ihm, and S.M. Hudson. 2010. Effect of the degree of deacetylation on the thermal decomposition of chitin and chitosan nanofibers. Carbohydr. Polym., 80(1): 291-295.

Pamies, R., R. Schmidt, M.D.C.L. Martínez, and J.G.D.L. Torre. 2010. The influence of mono and divalent cations on dilute and nondilute aqueous solutions of sodium alginates. Carbohydr. Polym., 80(1): 248-253.

Silverstein, R.M. and F.X. Webster. 1991. Spectrometric Identification of Organic Compounds USA: Wiley, $482 \mathrm{pp}$.

Sindhi, V., V. Gupta , K. Sharma, S. Bhatnagar, R. Kumari, and N. Dhaka. 2013. Potential applications of antioxidants. Journal of Pharmacy Research, 7(9): 828-835.

Smidsrod, O., A. Haug, and B. Larsen. 1963. Degradation of alginate in the presence of reducing compounds. Acta Chem. Scand., 17: 2628-2637.

Thomas, F., L.C.E Lundqvist, M. Jam, A. Jeudy, T. Barbeyron, C. Sandström, and M. Czjzek. 2013. Comparative characterization of two marine alginate lyases from Zobellia galactanivorans reveals distinct modes of action and exquisite adaptation to their natural substrate. The Journal of Biological Chemistry, 288(32): 23021-23037.

Ulan'ski, P. and J. Rosiak. 1992. Preliminary studies on radiation-induced changes in chitosan. International Journal of Radiation Applications and Instrumentation. Part C Radiation Physics and Chemistry, 39(1): 53-57.

Yudiati, E. and A. Isnansetyo. 2017. Characterizing the three different alginate type of Sargassum siliquosum. Ilmu Kelautan, 22(1): 7-14.

Yudiati, E., G.W. Santosa, M.R. Tontowi, S. Sedjati, E. Supriyantini, and M.Khakimah. 2018. Optimization of alginate alkaline extraction technology from Sargassum polycystum and its antioxidant properties. IOP Conf. Series: Earth and Environmental Science 139, 012052.

Yue, W. 2012. Preparation of low-molecular-weight hyaluronic acid by ozone treatment. Carbohydr. Polym., 89(2): 709-712.

Zhao, X., B. Li, C. Xue and L. Sun. 2012. Effect of molecular weight on the antioxidant property of low molecular weight alginate from Laminaria japonica. J. Appl. Phycol., 24(2), 295-300. 